\title{
Akuntansi Ditinjau Dari Kacamata Syariah dan Ekonomi Islam
}

\author{
Musta'an,", Herlina Kusuma Wardani \\ ${ }^{1}$ Universitas Sahid, Surakarta, Indonesia \\ ${ }^{2}$ Pusat Kajian Ekonomi dan Bisnis Syariah, Surakarta, Indonesia \\ *Email korenpondensi: mustaan57@gmail.com
}

Recieved 07-11-2017| Revised 18-11-2017| Accepted 23-11-2017

\begin{abstract}
Accounting is information submitted by companies through financial statements to provide a very clear picture of the various circumstances or conditions of the company. The purpose of this research is to know the concept of accounting in terms of the eyes of sharia and Islamic economics. The concept of Islamic accounting emerged long before the conventional accounting concepts that existed to date, even Islam itself has made a series of rules in accounting that have never been thought of by conventional accounting experts. The method used in this research is by using library method. Syariah Islam strongly supports the existence of accounting activities in every activity of activities undertaken by humans especially related to financial problems. The Islamic economic system studies and studies the people's economy by making the Qur'an and Hadith as its basis. Similarly, accounting, because the science of accounting related to the economic activities of people who have been described also in the Qur'an and Hadith. Islamic accounting in it covers issues that are not commonly thought of by capitalist accounting or conventional accounting. Human behavior while in the world will be judged in the afterlife. So that accounting is considered and considered as one of hisab or derivasinya is to advocate the good and forbid something bad.
\end{abstract}

Keywords: accounting, sharia, Islamic economy

How to cite: Musta'an, M., \& Wardani, H. (2017). Akuntansi Dari Kacamata Syariah Dan Ekonomi Islam. Jurnal Ilmiah Ekonomi Islam, 3(03), 181-185. doi:http://dx.doi.org/10.29040/jiei.v3i03.130

DOI: http://dx.doi.org/10.29040/jiei.v3i03.130

\section{Pendahuluan}

Akuntansi didefinisikan atau diartikan sebagai suatu sistem informasi yang menyediakan catatan-catatan atau laporan untuk para pemangku kepentingan mengenai berbagai kegiatan ekonomi dan kondisi atau keadaan perusahaan. Dengan kata lain, akuntansi merupakan suatu informasi yang disajikan oleh perusahaan melalui laporan keuangan untuk memberikan berbagai gambaran yang sangat jelas mengenai berbagai keadaan atau kondisi perusahaan (Sugiyarto, 2011)
Khusus di dalam upaya melaksanakan ajaran Islam yang memiliki kondisi serta berdimensi sosial ekonomi atau yang sering disebut dengan muamalah, memerlukan tingkat pemahaman serta penelitian yang lebih, karena aspek-aspek muamalah dalam pelaksanaannya lebih bersifat lentur dan dinamis dalam pengembangan serta penerapan hukumnya bila dibandingkan dengan ajaran Islam yang berdimensi dan bernilai ibadah (Tho'in dan Prastiwi, 2015). Demikian pula dengan akuntansi, yang tentunya penerapannya ke arah kegiatan dan aktivitas muamalah yang sifatnya dinamis tadi. Sehingga perkembangan 
sosial ekonomi masyarakat harus diikuti pula akuntabilitas kegiatan tersebut dengan pelaksaan akuntansi yang baik, guna menghindari adanya kelalaian antarpihak yang telah melakukan transaksi.

Akuntansi sendiri dipahami menjadi suatu sistem pembukuan atau yang sering kita kenal dengan istilah double entry. Pandangan akuntansi menurut sejarah awam serta terdapat pula diberbagai buku tentang teori-teori akuntansi yang ada, disebutkan dan diterangkan bahwa akuntansi muncul di negara Italia tepatnya pada abad ketiga belas (13) dari tangan seorang pendeta, yaitu Pendeta Luca Pacioli. Dimanan Luca Pacioli menulis buku dengan judul "Summade Arithmatica Geometria et Propotionalita" yang didalamnya memuat satu bab tentang Double Entry Accounting System. Oleh karena itu bila kita mendengar akuntansi syariah atau akuntansi syariah Islam, hal itu terasa sangat asing sekali.

Dalam sejarah menunjukkan bahwa setelah munculnya Islam di Semananjung Arab yang dipimpin langsung oleh Nabi Muhammad SAW serta dengan terbentuknya suatu daulah, yaitu Daulah Islamiah di Madinah. Dimana daulah tersebut kemudian di lanjutkan para Khulafaur'asyidin yang terdiri dari 4 sahabat, yaitu Abu Bakar, Umar, Usman, dan Ali terdapat adanya undang-undang akuntansi sebagai peraturan yang diterapkan baik untuk perorangan, untuk perserikatan, maupun untuk perusahaan, akuntansi wakaf, hak-hak pelarangan penggunaan harta, dan anggaran negara. Rasulullah Muhammad SAW sendiri juga telah mendidik secara khusus atau spesifik atas beberapa sahabat-sahabatnya untuk menangani keahlian sebagai akuntan yang disebut dengan hafazhatul amwal atau pengawas keuangan agar tercatat dengan baik dan dapat disajikan dengan runtut (Zaqzuq, 2003).

Dengan demikian, jika kita menengok sejarah sebenarnya konsep untuk akuntansi Islam muncul jauh sebelum adanya konsep akuntansi konvensional yang ada sampai saat ini, bahkan Islam sendiri telah membuat serangkaian kaidahkaidah di dalam akuntansi yang belum terpikirkan oleh para ahli akuntan konvensional. Sebagaimana yang telah terjadi juga selama ini pada berbagai ilmu pengetahuan yang ada, yang sudah digambarkan dan dinaskan melalui wahyu Allah SWT dalam al-Qur'an Surah An-Nahl ayat 89 yang berbunyi.

"(Dan ingatlah) akan hari (ketika) Kami bangkitkan pada tiap-tiap umat seorang saksi atas mereka dari mereka sendiri dan Kami datangkan kamu (Muhammad) menjadi saksi atas seluruh umat manusia. Dan Kami turunkan kepadamu Al Kitab (Al Quran) untuk menjelaskan segala sesuatu dan petunjuk serta rahmat dan kabar gembira bagi orang-orang yang berserah diri".

Oleh karena itu, Islam sangat menganjurkan kepada ummatnya agar tidak meremehkan prefesi akuntansi ini, agar setiap aktifitas atau kegiatan keuangan dapat tercatat dengan sebaikbaiknya.

\section{Metode Penelitian}

Metode penelitian yang digunakan dalam penelitian ini adalah berupa kajian pustaka yang diperoleh dari jurnal, buku, dan sumber-sumber lain yang relevan.

\section{Hasil Dan Pembahasan}

\subsection{Akuntansi}

Pengertian akuntansi menurut Smith dan Skousen (1995), akuntansi menurut pandangan Smith dan Skousen adalah sebuah kegiatan atau aktivitas jasa yang memiliki tujuan dalam rangka untuk menyediakan informasi kuantitatif (berupa perhitungan), terutama yang memiliki sifat pengambilan keputusan ekonomis dalam hal memberikan keputusan berupa sesuatu pilihanpilihan yang logis diantara berbagai tindakan alternatif.

Akuntansi menurut Charles, et al. (2007), mereka membuat definisi atau pengertian akuntansi. Akuntansi adalah suatu sistem informasi yang mampu mengukur kegiatan atau aktivitas bisnis, melakukan kegiatan pemprosesan data sampai menjadi suatu laporan, serta mengkomunikasikan hasilnya kepada para 
pengambil keputusan dalam hal ini adalah para manajer.

Menurut Suparwoto (1990), dia mendefinisikan atau membuat pengertian akuntansi sebagai suatu sistem atau kemampuan untuk melakukan pengukuran serta melakukan kegiatan pengelolaan yang berupa transaksi keuangan, kemudian memberikan hasil pengelolaan tersebut dalam bentuk informasi kepada berbagai pihak, baik pihak intern maupun pihak ekstern perusahaan itu sendiri. Pihak ekstern atau pihak luar perusahaan ini terdiri dari kreditur, investor, serikat buruh, lembaga perpajakan, pemerintah, dan masyarakat umum.

Sedangkan akuntansi menurut Warren et al (2005) sebagai berikut: mereka menjelaskan bahwa secara umum, akuntansi dapat didefinisikan atau dapat diartikan suatu sistem informasi yang menghasilkan sebuah laporan (laporan keuangan) kepada pihak-pihak yang berkepentingan mengenai aktivitas ekonomi dan kondisi organisasi atau perusahaan" (Warren et al., 2005). Selanjutnya oleh Littleton dalam (Muhammad, 2002) mendefinisikan: "tujuan pertama dan paling utama dari kegiatan akuntansi adalah untuk melaksanakan perhitungan periodik antara biaya yang dikeluarkan oleh perusahaan dan hasil atau prestasi yang diperoleh perusahaan . Konsep yang ada di atas tersebut merupakan inti dari teori akuntansi itu sendiri dan merupakan ukuran yang telah dijadikan sebagai suatu rujukan dalam rangka mempelajari akuntansi itu sendiri."

Bagi orang Islam atau muslim, yang menjadi sumber sumber hukum dan nilai adalah Al-Quran (kitab Allah SWT) dan Sunnah Nabi yang berupa Hadits. Konsekuensi yang harus diambil adalah apapun nilai yang dibutuhkan dalam melakukan berbagai kegiatan analisis serta perilaku ekonomi harus bersandar atau berdasar pada keduanya itu (Qur'an dan Hadits). Hal tersebut tercermin dari pandangan Islam mengenai bunga, gharar, dan maysir. Yang menjadi unik dan anehnya lagi, di cendekiawan Islam maupun kalangan ulama masih terjadi permasalahan berupa suatu pandangan yang berbeda mengenai apakah bunga itu sama atau identik dengan riba definisi atau pengertian riba menurut bahasa arab berarti peningkatan, tambahan, pertumbuhan atau ekspansi. Sedangkan pengertian riba menurut istilah sendiri, riba berarti pengambilan tambahan sebagai suatu atau sebuah syarat yang harus dibayarkan oleh pihak atau seorang peminjam kepada pihak yang memberikan pinjaman selain pinjaman pokoknya. Dalam pengertian yang telah diuraikan di atas, riba mempunyai makna yang sama dengan bunga sebagaimana konsensus atau kesepakatan bersama para fuqaha atau ahli fiqh (Kuncoro 2002).

Dengan demikian akuntansi yang sesuai dengan syariah adalah akuntansi yang berorientasi pada kepentingan-kepentingan sosial. Artinya di sini bahwa akuntansi tidak hanya sebagai suatu alat untuk menterjemahkan dan memaknai fenomena ekonomi dalam bentuk ukuran moneter saja, tetapi juga sebagai suatu metode atau suatu cara menjelaskan bagaimana sebuah kejadian ekonomi itu berjalan dalam masyarakat Islam itu sendiri. Dengan demikian, akuntansi syariah didalamnya termasuk isu yang tidak biasa dipikirkan oleh akuntansi kapitalis atau akuntansi konvensional. Perilaku manusia selama berada di dunia akan diadili diakhirat nanti. Sehingga akuntansi dinilai dan dipersepsikan sebagai salah satu hisab atau derivasi yaitu menganjurkan yang baik-baik dan melarang apaapa yang buruk.

\subsection{Syariah Islam}

Kata Syariah disini bila kita perhatikan berasal dari bahasa Arab, yaitu berasal dari kata Syara'a yang artinya adalah jalan. Dengan demikian, yang dimaksud dengan syariah Islam merupakan jalan yang ada dalam agama Islam atau suatu peraturan-peraturan yang ada dalam Islam.

Syariah merupakan sebuah sistem norma Ilahi yang mengatur hubungan atau interaksi antara manusia dengan sang Khaliq atau tuhannya, hubungan sesama manusia, serta hubungan manusia dengan alam semesta yang merupakan keseluruhan ciptaan Allah. 
Dari pengertian di atas, bahwasanya syariah juga mengatur hubungan muamalah atau sosial ekonomi, yang mana di dalamnya ada aktivitas kegiatan antar sesama manusia, sehingga untuk menghindari adanya kesalahan atau kelupaan dalam kegiatan ekonomi perlu adanya pencatatan atau akuntansi.

Dengan demikian syariah Islam sangat mendukung adanya kegiatan akuntansi dalam setiap aktivitas kegiatan yang dilakukan manusia khususnya yang berkaitan dengan masalah keuangan.

\subsection{Ekonomi Islam}

Menurut Manan (1992), Ekonomi Islam merupakan suatu ilmu pengetahuan sosial yang mempelajari dan mengkaji ilmu ekonomi rakyat, dimana penerapannya diilhami oleh nilai-nilai Islam (Tho'in, 2015). Sementar Halidai memberikan pengertian lain tentang pengertian ekonomi Islam. Ekonomi Islam ialah kumpulan dasardasar umum ekonomi yang disimpulkan yang bersumber dari al-Qur'an dan sunnah Rasulullah SAW yang ada hubungannya dengan berbagai permasalahan atau prolem ekonomi (Ali, 1998).

Dari pengertian di atas, sangatlah jelas bahwa sistem ekonomi Islam yang mempelajari dan mengkaji ekonomi rakyat dengan menjadikan al-Qur'an dan Hadits sebagai landasannya. Begitu pula akuntansi, karena ilmu akuntansi berkaitan dengan kegiatan ekonomi rakyat yang sudah diterangkan pula didalam al-Qur'an. Sebagaimana yang diterangkan dalam Surah alBaqarah ayat 282:

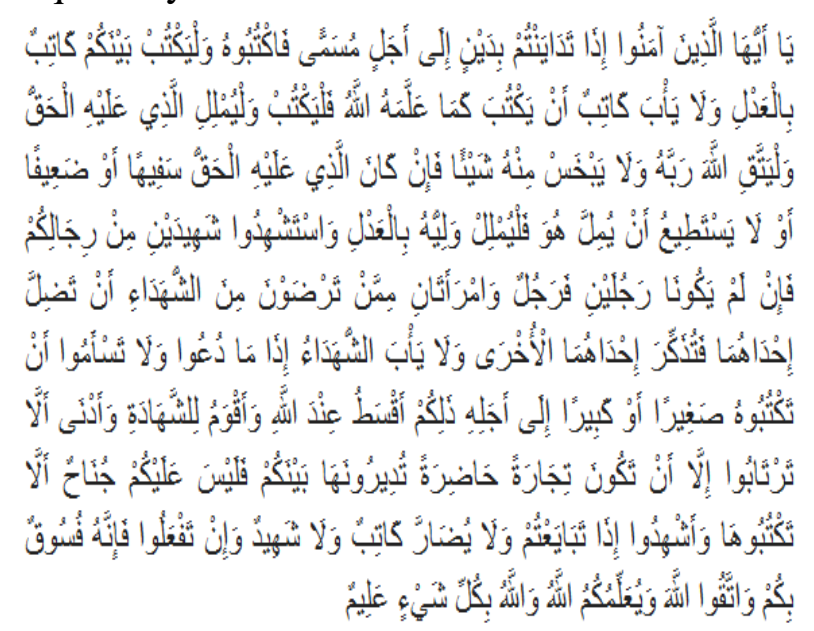

Yang artinya:
Hai orang-orang yang beriman, apabila kamu bermu'amalah tidak secara tunai untuk waktu yang ditentukan, hendaklah kamu menuliskannya. dan hendaklah seorang penulis di antara kamu menuliskannya dengan benar. dan janganlah penulis enggan menuliskannya sebagaimana Allah mengajarkannya, meka hendaklah ia menulis, dan hendaklah orang yang berhutang itu mengimlakkan (apa yang akan ditulis itu), dan hendaklah ia bertakwa kepada Allah Tuhannya, dan janganlah ia mengurangi sedikitpun daripada hutangnya. jika yang berhutang itu orang yang lemah akalnya atau lemah (keadaannya) atau Dia sendiri tidak mampu mengimlakkan, Maka hendaklah walinya mengimlakkan dengan jujur. dan persaksikanlah dengan dua orang saksi dari orang-orang lelaki (di antaramu). jika tak ada dua oang lelaki, Maka (boleh) seorang lelaki dan dua orang perempuan dari saksi-saksi yang kamu ridhai, supaya jika seorang lupa Maka yang seorang mengingatkannya. janganlah saksi-saksi itu enggan (memberi keterangan) apabila mereka dipanggil; dan janganlah kamu jemu menulis hutang itu, baik kecil maupun besar sampai batas waktu membayarnya. yang demikian itu, lebih adil di sisi Allah dan lebih menguatkan persaksian dan lebih dekat kepada tidak (menimbulkan) keraguanmu. (Tulislah mu'amalahmu itu), kecuali jika mu'amalah itu perdagangan tunai yang kamu jalankan di antara kamu, Maka tidak ada dosa bagi kamu, (jika) kamu tidak menulisnya. dan persaksikanlah apabila kamu berjual beli; dan janganlah penulis dan saksi saling sulit menyulitkan. jika kamu lakukan (yang demikian), Maka Sesungguhnya hal itu adalah suatu kefasikan pada dirimu. dan bertakwalah kepada Allah; Allah mengajarmu; dan Allah Maha mengetahui segala sesuatu.(Q.S. alBaqarah: 282) dalam (Muhammad, 2005).

\section{Kesimpulan}

Syariah Islam sangat mendukung adanya kegiatan akuntansi dalam setiap aktivitas kegiatan yang dilakukan manusia khususnya yang berkaitan dengan masalah keuangan. Sistem ekonomi Islam mempelajari dan mengkaji ekonomi rakyat dengan menjadikan alQur'an dan Hadits sebagai landasannya. Begitu 
pula akuntansi, karena ilmu akuntansi berkaitan dengan kegiatan ekonomi rakyat yang sudah diterangkan pula didalam al-Qur'an dan Hadits. Sehingga akuntansi dinilai dan dipersepsikan sebagai salah satu hisab atau derivasi yaitu menganjurkan yang baik-baik dan melarang apaapa yang buruk.

\section{Ucapan Terima Kasih}

Ucapan terima kasih yang tak terhingga saya haturkan kepada Pimpinan Universitas Sahid Surakarta dan Pimpinan Pusat Kajian Ekonomi dan Bisnis Syariah Surakarta yang mendukung penuh dalam penelitian kolaborasi ini. Tidak lupa pula saya haturkan terima kasih kepada reviewer yang bersedia mereview jurnal kami.

\section{Daftar Pustaka}

Ali, M. Daud. (1988). Sistem Ekonomi Islam, Zakat, dan Wakaf. Jakarta: UI Press.

Charles T. Horngren, dan Walter T. Harrison. (2007). Akunatnsi Jilid I. Jakarta: Penerbit Erlangga.

Kuncoro, Mudrajad dan Suharjono. 2002. Manajemen Perbankan, Teori dan Aplikasi. Yogyakarta: BPFE Yogyakarta.
Manan, M. A., (1992). Teori dan Praktik Ekonomi Islam.

Muhammad. (2005). Pengantar Akuntansi Syariah. Jakarta: Salemba Empat.

Smith dan Skousen. 1995. Akuntansi Intermediate. Jilid 2. Edisi Kedelapan. Jakarta. Erlangga.

Sugiyarto. (2011). Akuntansi Biaya. Jakarta: Universitas Terbuka.

Suparwoto, L., (1990). Analisis Keuangan Lanjutan I. Yogyakarta: BPFE Yogyakarta.

Tho'in, M. (2015). Konsep Ekonomi Islam Jalan Tengah (Kapitalis-Sosialis). Jurnal Ilmiah Ekonomi Islam, 1(03).

Tho'in, M., \& Prastiwi, I. E. (2015). Wakaf Tunai Perspektif Syariah. Jurnal Ilmiah Ekonomi Islam, 1(02).

Warren, Carl S, James M. Reeve, Philip E. Fess, tanpa tahun, Pengantar Akuntansi, Terjemahan oleh Aria Farahmita, Amanugrahani, dan Taufik H. (2005). Jakarta: Salemba Empat.

Zaqzuq, M.M. (2003). Islam dan Tantangan dalam Menghadapi Pemikiran Barat. Bandung: Pustaka Setia 